\title{
Educating future leaders in patient safety
}

This article was published in the following Dove Press journal:

Journal of Multidisciplinary Healthcare

19 September 2014

Number of times this article has been viewed

\author{
Agnès Leotsakos' \\ Antonella Ardolino ${ }^{2}$ \\ Ronny Cheung ${ }^{3}$ \\ Hao Zheng' \\ Bruce Barraclough ${ }^{4}$ \\ Merrilyn Walton ${ }^{5}$ \\ 'Patient Safety Programme, World \\ Health Organization, Geneva, \\ Switzerland; ${ }^{2}$ Wessex Deanery, \\ Winchester, UK; ${ }^{3}$ Imperial Healthcare \\ NHS, London, UK; ${ }^{4}$ The Australian \\ E Health Research Centre, Royal \\ Brisbane and Women's Hospital, \\ Brisbane, Australia; ${ }^{5}$ Sydney School \\ of Public Health, Faculty of Medicine, \\ University of Sydney, Sydney, Australia
}

Correspondence: Agnès Leotsakos Patient Safety Programme, World Health Organization, WHO/HIS/PSP, Avenue Appia 20, CH-I2II, Geneva, Switzerland $\mathrm{Tel}+4 \mid 22$ 79| 2567

Email leotsakosa@who.int
Abstract: Education of health care professionals has given little attention to patient safety, resulting in limited understanding of the nature of risk in health care and the importance of strengthening systems. The World Health Organization developed the Patient Safety Curriculum Guide: Multiprofessional Edition to accelerate the incorporation of patient safety teaching into higher educational curricula. The World Health Organization Curriculum Guide uses a health system-focused, team-dependent approach, which impacts all health care professionals and students learning in an integrated way about how to operate within a culture of safety. The guide is pertinent in the context of global educational reforms and growing recognition of the need to introduce patient safety into health care professionals' curricula. The guide helps to advance patient safety education worldwide in five ways. First, it addresses the variety of opportunities and contexts in which health care educators teach, and provides practical recommendations to learning. Second, it recommends shared learning by students of different professions, thus enhancing student capacity to work together effectively in multidisciplinary teams. Third, it provides guidance on a range of teaching methods and pedagogical activities to ensure that students understand that patient safety is a practical science teaching them to act in evidence-based ways to reduce patient risk. Fourth, it encourages supportive teaching and learning, emphasizing the need to establishing teaching environments in which students feel comfortable to learn and practice patient safety. Finally, it helps educators incorporate patient safety topics across all areas of clinical practice.

Keywords: patient safety education, WHO Patient Safety Curriculum Guide: Multiprofessional Edition

\section{Introduction}

Patient safety is fundamental to safe patient care. Although the principles and concepts of patient safety are acknowledged as a critical part of health professional education and training, many health care providers and academics remain uncertain as to how to integrate patient safety into health care education and clinical care, and are yet to integrate patient safety knowledge into bedside practice.

The importance of education and training in patient safety has been acknowledged for over a decade, ${ }^{1}$ yet, in most countries, it remains underutilized and undervalued as a method of addressing the many challenges facing contemporary health care. The World Health Organization (WHO) Patient Safety Curriculum Guide: Multiprofessional edition is a comprehensive curriculum designed to achieve that improvement in health care. The curriculum, when implemented, has the capacity to provide health care professionals with the underpinning and applied knowledge to incorporate patient 
safety principles into their practice, in a range of health care contexts.

The WHO Patient Safety Curriculum Guide: Multiprofessional Edition was launched in October 2011. It was based on the 2009 Patient Safety Curriculum Guide for Medical Schools, ${ }^{2}$ which was a first step in the process of establishing a patient safety curriculum for all health care professionals. $^{3}$

\section{Patient safety education worldwide}

Over the last decade, national patient safety and quality agencies as well as regional and global bodies have initiated Patient Safety Programs and have galvanized the support of political and health leaders worldwide (see Table 1). Patient safety learning in the workplace, ${ }^{4}$ coupled with greater recognition of the need to prepare health professional students for safe practice during their education, have led to a gradual transformation in the way that patient safety is viewed. While we are yet to reach a tipping point, many clinicians and leaders know that adverse events will only be reduced and managed effectively by health professionals when they are aware of and integrate patient safety principles and concepts into their daily practice.

Despite a plethora of patient safety initiatives, patient safety education for health professionals in the higher education sector has not kept up with workforce requirements. ${ }^{20-22}$ In developed countries, medication errors and surgical mistakes are routinely documented using incident reporting systems, but we are yet to see curricula contain the knowledge and skills required by health professional students to address and reduce patient harm. ${ }^{22}$ Patient safety has been incorporated into the higher education curricula slowly and somewhat sporadically. For example, a media article recently cited a leader's view that "patient safety is not incorporated fast enough in medical schools". ${ }^{23}$ A 2007 multi-institutional assessment of patient safety knowledge among medical trainee clinicians confirmed the need for patient safety education, but found that patient safety knowledge across a broad range of training, types of qualification, and specialties were substantially limited and that trainees were unable to self-assess their knowledge deficits. $^{24}$

A UK study of the impact of teaching, learning, and practicing patient safety in academic, organizational, and practice contexts highlighted that patient safety education needs to be more explicitly and integrated in health care curricula. ${ }^{25}$ The Commission on Education of Healthcare Professionals for the 21 st Century (although not focused specifically on patient safety) highlighted the weaknesses of health care professional training, including:

a mismatch of competencies to patient needs; curricular rigidities and static pedagogy, poor teamwork learning; narrow technical focus without broader contextual understanding; and weak leadership to improve healthsystem performance. ${ }^{26}$

The Commission recommended a system-wide reform to encourage adaptation, improvement, and flexibility in health care education generally and to create a health care professional workforce prepared for collaboration and trans- and interprofessional teamwork who are able to adapt to local requirements and needs. More recently, the WHO presented the general requirements necessary for incorporating patient safety in education and the skills inherent in that, such as teamwork and communication, human factors and safety, engagement of patients in their care, and wider contextual awareness and system-wide understanding of health care. ${ }^{27}$

Patient safety education in the developing world merits particular attention. Poor educational infrastructure, lack of resources and education materials, shortcomings of qualified educators because of low motivation or insufficient skills, and underfinancing of the higher education sector for health care professionals make patient safety education more challenging than in resource-rich countries. ${ }^{27}$ Integrating patient safety into undergraduate education in developing countries and in some transitional countries, which have advanced health care and education systems, is a significant challenge. A recent study in the People's Republic of China reported that, in addition to an already busy curriculum, leadership support, faculty engagement, course design, and teaching formats presented major challenges that deter the integration of patient safety education into existing curricula. ${ }^{28}$

In higher education for health care professionals, professionalism generally, but patient safety specifically, has been overlooked by many academic institutions. ${ }^{7,29}$ Integrating new patient safety and patient-centered curricula is important if education is to contribute to improving patient safety. Patient safety is not another subject to add to an already over-packed curricula, but serious thought is required as to how health professional teachers can integrate patient safety competencies into their clinical teaching and learning. Each health care profession should tailor patient safety principles and concepts to their own needs, limitations, and culture for positive changes to occur. ${ }^{30,31}$ 
Table I Some examples from a long list of national and global initiatives offering patient safety courses to health-care providers

\begin{tabular}{|c|c|c|c|}
\hline Institution & Country & Initiative & Reference \\
\hline National Health Service for Scotland & Scotland, UK & $\begin{array}{l}\text { NHS Scotland recommends multi-professional group } \\
\text { meetings and provides tools to educate health-care } \\
\text { workers in patient safety }\end{array}$ & 5 \\
\hline National Patient Safety Foundation & USA & $\begin{array}{l}\text { The Foundation has its own patient safety curriculum } \\
\text { with Continuing Medical Education (CME) modules to } \\
\text { complete }\end{array}$ & 6 \\
\hline $\begin{array}{l}\text { Australian Commission on Safety } \\
\text { and Quality in Health Care }\end{array}$ & Australia & $\begin{array}{l}\text { The Council has a syllabus for education and training in } \\
\text { patient safety; }\end{array}$ & 7 \\
\hline $\begin{array}{l}\text { Canadian Patient Safety Institute } \\
\text { (CPSI) }\end{array}$ & Canada & CPSI runs patient safety course for health-care leaders & 8 \\
\hline Betsy Lehman Center for Patient & USA & This Center was established by the Massachusetts & 9 \\
\hline Safety and Medical Error Prevention & & $\begin{array}{l}\text { Department of Public Health and sponsors patient safety } \\
\text { education and training programmes }\end{array}$ & \\
\hline Parliament, UK & UK & $\begin{array}{l}\text { The Parliament recognizes the need for incorporation of } \\
\text { education in patient safety for all health-care providers }\end{array}$ & 10 \\
\hline $\begin{array}{l}\text { Agency for Healthcare Research } \\
\text { and Quality (AHRQ) }\end{array}$ & USA & $\begin{array}{l}\text { AHRQ provides a wealth of information, tools and } \\
\text { resources for training in patient safety }\end{array}$ & 11 \\
\hline $\begin{array}{l}\text { Society for Quality in Healthcare } \\
\text { (SQHN) }\end{array}$ & Nigeria & $\begin{array}{l}\text { SQHN facilitates the continuous improvement of quality } \\
\text { and safety in health care in Nigeria through education } \\
\text { and accreditation }\end{array}$ & 12 \\
\hline $\begin{array}{l}\text { Council for Health Service } \\
\text { Accreditation of Southern Africa } \\
\text { (COHSASA) }\end{array}$ & South Africa & $\begin{array}{l}\text { Through its SafeCare initiative, COHSASA, assists African } \\
\text { health-care facilities to provide safe and quality health care } \\
\text { by providing technical resources, training } \\
\text { and financial incentives }\end{array}$ & 13 \\
\hline $\begin{array}{l}\text { World Organization of Family Doctors } \\
\text { (WONCA) }\end{array}$ & Global & $\begin{array}{l}\text { WONCA, provides resources and training for Quality } \\
\text { and Safety in family medicine worldwide }\end{array}$ & 14 \\
\hline Ministry of Health & Singapore & $\begin{array}{l}\text { Patient safety education is provided to hospital health- } \\
\text { care providers }\end{array}$ & $\begin{array}{l}\text { Personal e-mail } \\
\text { communication, January } \\
2013 \text {, by Dr Ong Biauw } \\
\text { Chi, Yong Loo Lin School of } \\
\text { Medicine, Singapore General } \\
\text { Hospital, Singapore }\end{array}$ \\
\hline $\begin{array}{l}\text { Patient Safety Education } \\
\text { Project (PSEP) }\end{array}$ & Global & $\begin{array}{l}\text { Is an international collaboration for the education of } \\
\text { teams of healthcare professionals and administrators in } \\
\text { patient safety issues }\end{array}$ & 15 \\
\hline $\begin{array}{l}\text { Institute for Healthcare } \\
\text { Improvement (IHI) }\end{array}$ & USA & $\begin{array}{l}\text { The 'Open School' for Health Professions is a hub of } \\
\text { free online courses on quality improvement topics and } \\
\text { patient safety }\end{array}$ & 16 \\
\hline $\begin{array}{l}\text { Organization for Safety and Prevention } \\
\text { (OSAP) and the International Dental } \\
\text { Federation (FDI) }\end{array}$ & Global & $\begin{array}{l}\text { Both professional organizations address issues related } \\
\text { to the WHO Patient Safety Curriculum Guide and } \\
\text { deliver educational sessions on patient safety }\end{array}$ & $\begin{array}{l}\text { Personal e-mail } \\
\text { communication, June 2013, } \\
\text { by Professor Enrique Acosta, } \\
\text { National Autonomous } \\
\text { University of Mexico }\end{array}$ \\
\hline $\begin{array}{l}\text { International Alliance of Patients' } \\
\text { Organizations (IAPO) }\end{array}$ & Global & $\begin{array}{l}\text { IAPO provides patient safety resources and a toolkit for } \\
\text { patients and health-care professionals }\end{array}$ & 17 \\
\hline $\begin{array}{l}\text { World Health Organization's } \\
\text { Patient Safety Programme (PSP) }\end{array}$ & & $\begin{array}{l}\text { PSP provides webinars and educational materials in its } \\
\text { quest to strengthen and improve patient safety research } \\
\text { in all countries around the world. }\end{array}$ & 18,19 \\
\hline
\end{tabular}

\section{The role of education and training in patient safety}

Patient safety education of health care professionals has been given little attention, resulting in students' limited understanding of the risk in health care and the importance of strengthening systems. Furthermore, the professional ethos of extending a health care provider's responsibilities beyond the care of their individual patients to ensuring safe delivery of health care as a whole is not often conveyed or obvious to students. There is also little emphasis in much curricula or 
practice of multi-professional teamwork and communication about the causes of harm and how to protect patients. Some of the factors that contribute to this situation are:

- Lack of recognition by health care educators that teaching and learning patient safety should be an essential part of the undergraduate curricula for health care students, and that patient safety skills can be taught. ${ }^{29,32}$

- Lack of familiarity of educators or trainers to teach patient safety as a new area of knowledge and learning. ${ }^{33}$

- Reluctance by academic institutions and educators to teach health care students knowledge that is outside the clinical discipline, often because of existing full curricula. $^{29}$

- A historical emphasis on treatment of disease rather than prevention of illness creates a culture that finds it difficult to give merit to a "non-event" (ie, a preventable adverse event). ${ }^{34}$

- Educational silos when different disciplines are taught separately, which is contrary to the interdisciplinary team approach stressed by patient safety education. ${ }^{35,36}$

- Entrenched attitudes regarding the traditional teacher-student relationship - a relationship that may be hierarchical and competitive, ${ }^{32}$ and in which an "expert" disseminates information to the student. ${ }^{21,34}$

Undergraduate education plays a major role in the promulgation of evidence-based competencies incorporating concepts, knowledge, and skills in patient safety. ${ }^{21,37}$ Teaching patient safety can have a positive impact by promoting the competencies needed for safe health care.

\section{The WHO Patient Safety Curriculum Guide: Multiprofessional Edition}

Patient safety is recognized as the responsibility of all health care professionals ${ }^{38-42}$ and not specific to one profession;

Table 2 The WHO Patient Safety Curriculum Guide: Multiprofessional Edition

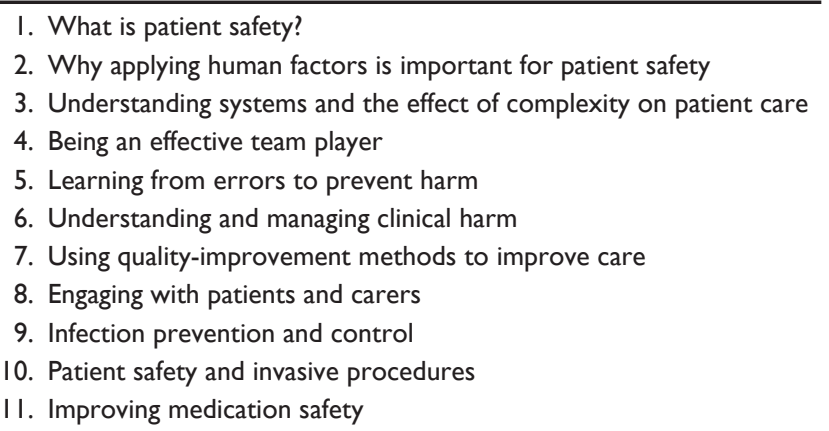

Note: Copyright 20I I. World Health Organization. Patient Safety Curriculum Guide: Multiprofessional Edition. Geneva: World Health Organization; 20II. Available from: http:/l whqlibdoc.who.int/publications/201 I/9789241501958_eng.pdf. Accessed November I5, $2012 .^{27}$ therefore, all health professional learning should integrate patient safety competencies into clinical teaching and skills development.

The 2011 WHO Multi-professional Patient Safety Curriculum Guide was developed to satisfy the demand for a single coordinated, systems-based, team-dependent approach, to ensure patient safety learning is delivered in an integrated way. This encourages shared learning across professions, as well as building an organizational culture of safety in all health care systems - a need highlighted by the Commission on Education of Healthcare Professionals for the 21 st Century. ${ }^{26}$

The WHO Patient Safety Curriculum Guide: Multiprofessional Edition is an updated, evidence-based edition of the WHO Patient Safety Curriculum Guide for Medical Schools. It is divided into two parts. Part A provides practical support and guidance to educators on how to deliver the patient safety topics described in Part B and also offers background information to educators on how to select and teach each topic, makes suggestions on how to integrate patient safety teaching, and provides techniques for exploring how patient safety learning could fit into the institution's existing curricula. Clear examples are provided throughout Part A on how patient safety might be taught. Part B describes eleven patient safety topics (see Table 2) that cover a wide range of contexts in which patient safety learning can occur. ${ }^{27}$ The ready-to-teach topics can be used either as a whole or on a per-topic basis. They provide the foundation for undergraduate and graduate health care students to obtain the core knowledge and skills required to practice safely. Educators can choose topics to introduce into their curricula as guided by institutional requirements, resources, and their capacity. A number of different educational approaches are suggested for each topic.

The underpinning principles of the WHO Curriculum Guide are to support educators to teach patient safety. It is easily adaptable to local patient safety requirements and written in an easily understood language so that it applies to all countries, cultures, and contexts.

Evaluation of WHO Patient Safety Curriculum Guide: Multiprofessional Edition took place in 12 pilot sites, which included dental, nursing, midwifery, and pharmacy schools around the world, and ten complementary test sites. Outcomes of the evaluation study are available at the WHO website. ${ }^{43}$

\section{How to advance patient safety education}

Taking into account the suggestions of The Commission on Education of Healthcare Professionals for the 21st Century, the WHO Curriculum Guide provides instructions, practical 
recommendations, and technical content to address educational weaknesses that include the mismatch of competencies to patient needs, the rigidity of curricula and static pedagogy, and poor teamwork learning.

In addition, the Curriculum Guide helps build capacity for patient safety education in all countries across the whole socioeconomic spectrum. It prioritizes and describes what to teach and how to teach, in terms of patient safety, in a single volume. The guide helps in five ways (described below) to advance patient safety education, taking advantage of global trends and opportunities for educational reforms, focusing particularly on the need to introduce patient safety into health care professionals' curricula.

\section{International scope and context}

The Commission on Education of Healthcare Professionals for the 21 st Century states that, because of global interdependence in health and the fact that universities and educational institutions are broadening their traditional roles, "educational reforms are timely for health professional education to meet standards and needs of 21 st century". ${ }^{26}$ The Curriculum Guide attempts to encourage both health care educators and students worldwide to share common understanding, knowledge, and skills in patient safety to assure coverage of high-quality and safe services, as members of locally responsive teams operating within a culture of safety and globally connected members advancing patient safety definitions, content, and solutions. The content of the Curriculum Guide takes into account the wide variety of contexts in which health care educators and students teach and learn. The WHO Expert Working Group, composed of more than 50 international experts, was involved in the development of the curriculum to ensure its cultural appropriateness and global reach. Teaching and assessment strategies are designed to take into account both the diversity in available resources and cultural differences that could affect the learning environment. As a resource that is freely available to all health care systems globally, the Curriculum Guide reinforces the ethos that safety is a right for all patients, and not a luxury confined to better-resourced health care systems.

\section{Team-based approach to patient safety}

The second aspect of the Curriculum Guide is about building student competencies in relation to patient needs. This is reflected in the multi-professional perspective of the Curriculum Guide, and the context of educating health care students, irrespective of their chosen profession, to understand and practice patient safety. It supports and promotes a collaborative, nonhierarchical way of delivering care. Multidisciplinary teamworking is increasingly part of the role of doctors, midwives, nurses, pharmacists, and even dentists, who have traditionally provided their services in isolation from other health care services. The multi-professional WHO Curriculum Guide is the first coordinated product of its kind to embrace a global outlook and a multi-professional perspective within a systems approach. It demonstrates how patient safety learning can be delivered in an integrated way. This approach encourages shared learning by students of different professions and a better understanding of the need for joint working, thus enhancing student capacity to work together effectively in future practice. This perspective pervades all of the guide's topic chapters. Knowledge and skill requirements are described for students to enable them to become effective team players, deliver accurate and timely cross-disciplinary communication, and act ethically with respect for colleagues. It also prepares them for working in a culture that does not identify all errors and mistakes as blameworthy but only those made in the context of working in a complex system. Within this context, each topic chapter provides examples of case studies drawn from different health care settings and professional groups and highlights a range of tools and resources reflecting the multi-professional viewpoint. Case studies are regarded as an effective learning tool in interdisciplinary education. In the Curriculum Guide, case studies have been described to highlight the risks to patients from a multi-professional perspective and to bring the Curriculum to life by giving real examples of what can go wrong and how effective teamwork can have an immediate and positive impact on patient safety.

\section{Patient safety beyond the classroom}

To address the challenge of rigid curricula and static pedagogy, the WHO Curriculum Guide recommends the use of many, different learning channels to provide balanced guidance for didactic teaching. Recommended teaching methods include active instruction of students through a range of pedagogical activities, including patient and health professional buddying, role-modeling, undertaking hospital-based improvement and team-based learning projects, independent studies, and participating in simulation training. The WHO Curriculum Guide provides lists of websites and links to resources and information on patient safety for both learners and teachers. The theme of educational collaboration runs across all the topic chapters as an instrument for enhancing the sharing of information, experiences, and synergies between institutions. The importance of extending educational activities beyond the use of static curricula and the university boundaries is highlighted, and educators are encouraged to use instruments such as networking and partnerships with other universities in 
the same country and internationally for academic exchange and practical learning.

The Curriculum Guide is designed to make use of multiple dissemination channels so that its teaching resources, tools, slides, case studies, and references are available worldwide through printed copies, websites (for example, http://www.who. int/patientsafety/education/curriculum/en/index.html, http:// www.who.int/patientsafety/education/vincristine download/ en/index.html, http://www.who.int/patientsafety/research/ online course/en/index.html), CD-ROMs, instruction in WHO workshops, and WHO e-learning.

\section{Grounded in sound educational theory and practice}

Every country and institution has its own unique traditions and culture of educating health care professionals. Hierarchical teaching styles, stagnant pedagogy, and professional silos have a negative impact on student learning generally, but specifically for patient safety. The Curriculum Guide encourages supportive teaching and learning, emphasizing the importance of establishing an environment in which students feel comfortable to learn and practice patient safety. The chapters emphasize that educators are role models for students; their clinical knowledge and patient safety skills are explicit within training the next generation of health care providers. At the same time, WHO Curriculum Guide empowers students to recognize their educators as embodying an open safety culture and instilling the professional ethos of open reporting and safety consciousness in them.

\section{Integration into existing curricula}

The content and structure of the WHO Curriculum Guide is designed to support educators in incorporating priority patient safety topics into all areas of practice and all health care professions. The topic modules of the Curriculum Guide are not taught as a stand alone course, but can be incorporated into existing teaching of, for example, microbiology, obstetrics, physiology, etc. Addressing patient safety is integral to all health care professionals' clinical practice and is not a subject to be studied in isolation. The eleven priority topics are self-contained, ready-to-teach modules that can be used as a whole, modified, or taught on a per-topic basis.

Almost all health care curricula have limited space and time for the addition of new courses. Each patient safety topic from the Curriculum Guide is designed to be easily integrated into existing curricula, although integration of all topics is necessary for the development of safe clinicians.

\section{Conclusion}

The WHO Curriculum Guide is a freely available resource for implementing patient safety education. As a comprehensive guide, it contains information for all levels of faculty and students and lays the foundation for capacity-building in the essential patient safety principles and concepts. Part A of the Curriculum Guide is a rich resource for educators involved in the development of health care curricula.

Its global, multi-professional perspective reflects the need to address patient safety on a system-wide basis, involving all health care professionals and students learning in an integrated way how to operate within a culture of safety, openness, and reporting, which should be the cornerstones of future health care systems worldwide. It is through such an integrated approach including all future health care professionals that we can change, at pace and scale, the global health care environment to one in which health-related harm becomes a rare event.

\section{Author contributions}

Agnès Leotsakos (main author): writing of the paper; execution of the study. Antonella Ardolino: desk research and writing of the paper; Ronny Cheung: desk research and writing of the paper; Hao Zheng: writing of the paper, execution of the study; Bruce Barraclough: execution of the study, revised and approved final version of the paper; Merrilyn Walton: editing of the paper and execution of the study.

\section{Acknowledgments}

Enrique Acosta-Gio, National Autonomous University of Mexico, Mexico; Jean Barry, International Council of Nurses, Switzerland; Jiri Vlcek, Charles University, Czech Republic; Nermin Yamalik, Hacettepe University, Turkey, Eleni Azarias and Reema Harrison, Sydney University, Australia.

\section{Disclosure}

The authors report no conflicts of interest in this work.

\section{References}

1. Kohn LT, Corrigan JM, Donaldson MS, editors. To Err is Human: Building a Safer Health System. Washington, DC: National Academy Press; 1999.

2. WHO Patient Safety Curriculum Guide for Medical Schools. Geneva: World Health Organization; 2009. Available from: http://whqlibdoc.who. int/publications/2009/9789241598316_eng.pdf. Accessed June 17, 2013.

3. Walton M, Woodward H, Van Staalduinen S, et al; Expert Group convened by the World Alliance of Patient Safety, as Expert Lead for the Sub-Programme. The WHO patient safety curriculum guide for medical schools. Qual Saf Health Care. 2010;19:542-546.

4. Emanuel L, Walton M, Hatlie M. The Patient Safety Education Project: an international collaboration. In: Henriksen K, Battles JB, Keyes MA, Grady ML, editors. Advances in Patient Safety: New Directions and Alternative Approaches. Rockville, MD: Agency for Healthcare Research and Quality; 2008. 
5. Patient Safety and Clinical Skills [webpage on the Internet]. Edinburgh: NHS Education for Scotland. Available from: http://www.nes.scot. nhs.uk/education-and-training/by-theme-initiative/patient-safety.aspx. Accessed June 17, 2013.

6. Patient Safety Curriculum [webpage on the Internet]. Boston, MA: National Patient Safety Foundation. Available from: http://www.npsf. org/online-learning-center/patient-safety-curriculum-2/. Accessed June 17, 2013.

7. Australian Commission on Safety and Quality in Health Care [homepage on the Internet]. Sydney: Australian Commission on Safety and Quality in Health Care. Available from: http://www.safetyandquality.gov.au/. Accessed June 17, 2013.

8. Education and Professional Development [webpage on the Internet]. Edmonton: Canadian Patient Safety Institute. Available from: http:// www.patientsafetyinstitute.ca/English/education/Pages/default.aspx. Accessed June 17, 2013.

9. Betsy Lehman Center for Patient Safety and Medical Error Prevention [webpage on the Internet]. Boston, MA: Center for Health Information and Analysis. Available from: http://www.mass.gov/chia/ gov/betsylehman.html. Accessed June 17, 2013.

10. Education and training curricula [webpage on the Internet]. London: UK Parliament; 2009. Available from: http://www.parliament.thestationery-office.co.uk/pa/cm200809/cmselect/cmhealth/151/15111 htm. Accessed June 17, 2013.

11. AHRQ Patient Safety Tools and Resources [webpage on the Internet] Rockville, MD: Agency for Healthcare Research and Quality; 2013. Available from: http://www.ahrq.gov/qual/pstools.htm. Accessed June 17, 2013

12. The Society for Quality in Healthcare in Nigeria (SQHN). Available from: http://sqhn.org/. Accessed June 17, 2013.

13. SafeCare Foundation [webpage on the Internet]. The Council for Health Service Accreditation of Southern Africa (COHSASA). Available from: http://www.cohsasa.co.za/safecare-initiative. Accessed June 17, 2013.

14. WONCA Working Party: Education [webpage on the Internet]. Bangkok: World Organization of Family Doctors (WONCA). Available from: http://www.globalfamilydoctor.com/groups/WorkingParties/ Education.aspx. Accessed June 17, 2013.

15. The Patient Safety Education Program [homepage on the Internet] Chicago, IL: Patient Safety Education Projects (PSEP). Available from: http://patientsafetyeducationproject.org/index.php. Accessed June 17, 2013.

16. The Institute for Healthcare Improvement [homepage on the Internet] Open School for Health Professions. Available from: http://www.ihi. org/education/ihiopenschool/Pages/default.aspx. Accessed June 17, 2013.

17. IAPO Patient Safety Toolkit [webpage on the Internet]. London: International Alliance of Patients' Organizations (IAPO). Available from http://www.patientsorganizations.org/showarticle.pl?id=803\&n=37202. Accessed June 17, 2013.

18. Patient safety research: introductory course (on-line) [webpage on the Internet]. Geneva: World Health Organization. Available from: http:// www.who.int/patientsafety/research/online_course/en/index.html. Accessed June 17, 2013.

19. Education and Training [webpage on the Internet]. Geneva: World Health Organization. Available from: http://www.who.int/patientsafety/ education/en/. Accessed June 17, 2013.

20. Walton M, Barraclough B, Van Staalduinen S, Elliott SL. An educational approach to improving healthcare safety and quality. J Evid Based Med. 2009;3:136-142.

21. Johnstone MJ, Kanitsaki O. Clinical risk management and patient safety education for nurses: a critique. Nurse Educ Today. 2007;27: $185-191$.
22. Patey R, Flin R, Cuthbertson BH, et al. Patient safety: helping medical students understand error in healthcare. Qual Saf Health Care. 2007;16: 256-259.

23. Blumenthal D, Ganguli I. Patient safety: conversation to curriculum. The New York Times. January 25, 2010. Available from: http://www.nytimes. com/2010/01/26/health/26error.html. Accessed June 17, 2013.

24. Kerfoot BP, Conlin PR, Travison T, McMahon GT. Patient safety knowledge and its determinants in medical trainees. J Gen Intern Med. 2007;22:1150-1154.

25. Pearson P, Steven A, Howe A, et al. Patient safety in health care professional educational curricula: examining the learning experience. 2009.

26. Frenk J, Chen, L, Bhutta ZA, et al. Health professionals for a new century: transforming education to strengthen health systems in an interdependent world. Lancet. 2010;376:1923-1958.

27. Patient Safety Curriculum Guide: Multi-professional Edition. Geneva: World Health Organization; 2011. Available from: http://whqlibdoc. who.int/publications/2011/9789241501958_eng.pdf. Accessed November 15, 2012.

28. Nie Y, Li, L, Duan Y, et al. Patient safety education for undergraduate medical students: a systematic review. BMC Med Educ. 2011;11:33.

29. Walton M. Teaching patient safety to clinicians and medical students. Clin Teach. 2007;4:224-231.

30. Leung G, Patil NG, Ip MS. Introducing patient safety to undergraduate medical students - a pilot program delivered by health care administrators. Med Teach. 2010;32:e547-e551.

31. Leung G, Patil NG. Patient safety in the undergraduate curriculum: medical students' perception. Hong Kong Med J. 2010;16:101-105.

32. Sandars J, Bax N, Mayer D, Wass V, Vickers R. Educating undergraduate medical students about patient safety: priority areas for curriculum development. Med Teach. 2007;29:60-61.

33. Walton MM, Elliott SL. Improving safety and quality: how can education help? Med J Aust. 2006;184(Suppl 10):S60-S64.

34. Stevens DP. Finding safety in medical education. Qual Saf Health Care. 2002;11:109-110.

35. O'Grady ET. Advanced practice registered nurses: the impact on patient safety and quality. In: Hughes RG, editor. Patient Safety and Quality: An Evidence-Based Handbook for Nurses. Rockville, MD: Agency for Healthcare Research and Quality; 2008:601-620.

36. Collaborative Education to Ensure Patient Safety, Council on Graduate Medical Education and National Advisory Council on Nurse Education and Practice. Sep 2000. Available from: http://www.hrsa.gov/advisorycommittees/bhpradvisory/cogme/Publications/collaborativeedu.pdf. Accessed June 23, 2014.

37. Flanagan B, Nestel D, Joseph M. Making patient safety the focus: crisis resource management in the undergraduate curriculum. Med Educ. 2004;38:56-66.

38. Fischer MA, Mazor KM, Baril J, Alper E, DeMarco D, Pugnaire M. Learning from mistakes. Factors that influence how students and residents learn from medical errors. J Gen Intern Med. 2006;21:419-423.

39. Eisenberg JM. Continuing education meets the learning organization: the challenge of a systems approach to patient safety. J Contin Educ Health Prof. 2000;20:197-207.

40. Institute of Medicine. Crossing the Quality Chasm: A New Health System for the 21st Century. Washington, DC: National Academy Press; 2001.

41. Valdez AM. So much to learn, so little time: educational priorities for the future of emergency nursing. Adv Emerg Nurs J. 2009;31:337-353.

42. Neudorf K, Dyck N, Scott D, Davidson Dick D. Nursing education: a catalyst for the patient safety movement. Healthc Q. 2008;11:35-39.

43. Sehgal NL, Fox M, Vidyarthi AR, et al; Triad for Optimal Patient Safety Project. A multidisciplinary teamwork training program: the Triad for Optimal Patient Safety (TOPS) experience. J Gen Intern Med. 2008;23(12):2053-2057. 


\section{Publish your work in this journal}

The Journal of Multidisciplinary Healthcare is an international, peerreviewed open-access journal that aims to represent and publish research in healthcare areas delivered by practitioners of different disciplines. This includes studies and reviews conducted by multidisciplinary teams as well as research which evaluates the results or conduct of such teams or health-

care processes in general. The journal covers a wide range of areas and welcomes submission from practitioners at all levels, from all over the world. The manuscript management system is completely online and includes a very quick and fair peer-review system. Visit http://www.dovepress. com/testimonials.php to read real quotes from published authors.

Submit your manuscript here: http://www.dovepress.com/journal-of-multidisciplinary-healthcare-journal 